\title{
A prospective study of antituberculous drug-induced hepatotoxicity in an area endemic for liver diseases
}

\author{
Hoda A. Makhlouf • Ahmed Helmy • \\ Ehab Fawzy · Madiha El-Attar · Hebat Alla G. Rashed
}

Received: 1 February 2008/Accepted: 19 June 2008/Published online: 25 July 2008

(C) Asian Pacific Association for the Study of the Liver 2008

\begin{abstract}
Purpose Identification of risk factors associated with antituberculosis drug-induced hepatotoxicity (anti-TB$\mathrm{DIH})$ is important, especially in endemic area for TB and liver disease. This study assessed the incidence and risk factors of anti-TB-DIH in upper Egyptian patients treated for active pulmonary and extra-pulmonary TB.

Methods A total of 100 consecutive TB patients were prospectively followed up both clinically and biochemically before and during their course of anti-TB therapy with daily doses of isoniazid, rifampin, ethambutol, and pyrazinamide, or streptomycin.

Results Anti-TB-DIH developed in 15 (15\%) patients within 15-60 days (median: 30 days) from the onset of therapy. Liver function normalized in $10(60 \%)$ patients within 2 weeks from cessation of therapy. No recurrence of DIH was observed after reintroduction of therapy. Only 1 patient died from fulminant hepatic failure despite discontinuation of all anti-TB drugs. By univariate analysis, patients with antiTB-DIH had more pre-existing liver disease $(P=0.024$; OR:
\end{abstract}

\section{H. A. Makhlouf}

Department of Chest Diseases, Faculty of Medicine,

Assiut University, Assiut 71111, Egypt

A. Helmy $\cdot$ E. Fawzy $\cdot$ M. El-Attar

Department of Tropical Medicine \& Gastroenterology,

Faculty of Medicine, Assiut University, Assiut 71111, Egypt

\section{A. Helmy ( $₫)$}

Gastroenterology Section, Department of Medicine MBC 46,

King Faisal Specialist Hospital \& Research Center,

PO Box 3354, Riyadh 11211, Saudi Arabia

e-mail: ahsalem10@hotmail.com

H. A. G. Rashed

Department of Clinical Pathology, Faculty of Medicine,

Assiut University, Assiut 71111, Egypt
3.60; 95\% CI: 1.16-11.18), lower body mass index (BMI; $P=0.037$; OR: $3.73 ; 95 \%$ CI: 1.04-10.56), lower serum albumin $(P=0.035$; OR: $3.31 ; 95 \%$ CI: $1.04-10.56)$, and more extensive disease ( $P=0.033$; OR: 3.50 ; 95\% CI: $1.11-11)$. Age, gender, raised baseline transaminases level, inclusion of pyrazinamide, and inactive hepatitis B or C carrier state were not significant risk factors of DIH. Using multivariate regression analysis, only pre-existing liver disease and lower BMI of $20 \mathrm{~kg} / \mathrm{m}^{2}$ or less were independent predictors of DIH ( $P=0.024$ and $P=0.047$, respectively).

Conclusion Anti-TB-DIH is not uncommon, needs early recognition and treatment, and is more in patients with preexisting liver disease and low BMI.

Keywords Drug-induced liver disease ·

Drug-induced hepatitis - Side effects - Adverse reactions .

Pulmonary tuberculosis $\cdot$ Risk factors

$\begin{array}{ll}\text { Abbreviations } & \\ \text { ALT } & \text { Alanine transaminase } \\ \text { anti-TB-DIH } & \text { Antituberculosis drug-induced } \\ & \text { hepatotoxicity } \\ \text { AST } & \text { Aspartate transaminase } \\ \text { CI } & \text { Confidence interval } \\ \text { DIH } & \text { Drug-induced hepatotoxicity } \\ \text { EMB } & \text { Ethambutol } \\ \text { HBV } & \text { Hepatitis B virus } \\ \text { HCV } & \text { Hepatitis C virus } \\ \text { INH } & \text { Isoniazid } \\ n & \text { Number } \\ \text { OR } & \text { Odds ratio } \\ \text { PZA } & \text { Pyrazinamide } \\ \text { RIF } & \text { Rifampin } \\ \text { SD } & \text { Standard deviation } \\ \text { TB } & \text { Tuberculosis }\end{array}$




\section{Introduction}

Tuberculosis (TB) is endemic in developing countries, including Egypt, and is increasingly recognized in developed countries, especially in immune-compromised patients [1]. Despite the efficacy of anti-TB agents, hepatotoxicity from first-line drugs - isoniazid (INH), rifampin (RIF), and pyrazinamide (PZA) - may result in $\operatorname{drug}(\mathrm{s})$ discontinuation, de novo liver disease, or exacerbation of pre-existing ones [2-6]. Anti-TB drug-induced hepatotoxicity (DIH) ranges from nonspecific transaminasitis to fulminant hepatic failure $[5,6]$.

The exact factors associated with anti-TB-DIH are unknown. However, alcohol abuse, increasing age, preexisting liver disease, slow acetylators, and severe malnutrition have been reported as risk factors [4, 7]. Recent studies suggested that polymorphism and reduced activity of hepatic $\mathrm{N}$-acetyl-transferase-2 genes and glutathione$S$-transferase contribute to DIH [8].

The incidence, pattern, and predictors of anti-TB-DIH have not been prospectively studied before in Egypt, where chronic liver diseases secondary to hepatitis B virus (HBV) and hepatitis $\mathrm{C}$ virus (HCV) infections and/or schistosomiasis are prevalent. Anti-TB-DIH in such endemic areas is difficult to evaluate and need to be differentiated from exacerbation of pre-existing diseases and from de novo infections. Therefore, the aims of this study were to determine the incidence and pattern of anti-TB-DIH in patients with active pulmonary and extra-pulmonary TB and to assess the independent risk factors associated with DIH in these patients.

\section{Patients and methods}

\section{Patients}

This prospective study was conducted in the Chest Outpatient Clinic, Assiut University Hospital, Assiut, Egypt, from October 8, 2004, till January 4, 2005. Inclusion criteria comprised patients with active pulmonary or extrapulmonary TB, who were going to start anti-TB drug regimen irrespective of their liver disease status. Of 104 consecutive patients registered in the clinic during the study period, 4 patients did not complete their follow-up and were excluded. All patients gave written informed consent and the study was approved by the Faculty of Medicine Research Ethics Committee.

\section{Anti-TB regimen}

Total treatment period was 6 months including intensive and continuation phases ( 2 and 4 months, respectively). The intensive phase comprised INH $\left(5 \mathrm{mg} / \mathrm{kg} \mathrm{day}^{-1}\right.$; maximum $300 \mathrm{mg} / \mathrm{day}), \mathrm{RIF}\left(10 \mathrm{mg} / \mathrm{kg} \mathrm{day}^{-1}\right.$; maximum $600 \mathrm{mg} /$ day), EMB (15-20 mg/kg day ${ }^{-1}$ ), and PZA (20-25 $\mathrm{mg} / \mathrm{kg} \mathrm{day}{ }^{-1}$ ), or streptomycin. The continuation phase comprised daily similar doses of INH and RIF.

\section{Diagnosis of DIH}

Anti-TB-DIH was diagnosed according to International Union against Tuberculosis and Lung Disease [9] as follows:

1. Normalization of liver enzymes and resolution of signs and symptoms of hepatotoxicity after withdrawal of all anti-TB drugs, and

2. Presence of at least one of the following:

i. A rise to more than 2 the upper limit of normal (ULN) level of alanine transaminase (ALT) and/or aspartate transaminase (AST) [10-12].

ii. A rise in total serum bilirubin to more than 1.5 $\mathrm{mg} / \mathrm{dl}$.

iii. Any increase in AST and/or ALT above pretreatment levels together with anorexia, nausea, vomiting, and jaundice.

\section{Baseline assessment}

Pretreatment evaluation included clinical history, physical examination, body mass index (BMI = body weight $(\mathrm{kg}) /$ [height $(\mathrm{m})]^{2}$ ), chest radiographs, abdominal ultrasonography, complete blood cell count, liver function tests (LFTs), and hepatitis markers. Samples from HBsAg, antiHB core antibody (anti-HBc), and/or anti-HCV antibodypositive patients were tested for $\mathrm{HBV}$ DNA and $\mathrm{HCV}$ RNA, respectively. A BMI of less than $20 \mathrm{~kg} / \mathrm{m}^{2}$ was considered as low. Hypoalbuminemia was defined as serum albumin level of less than $3.5 \mathrm{mg} / \mathrm{dl}$. The ULN in our laboratory is $41 \mathrm{IU} / 1$ for ALT and $38 \mathrm{IU} / 1$ for AST.

\section{Follow-up}

Patients were followed closely in a specialized clinic by a chest physician and a hepatologist fortnightly over the first 2 months, then monthly till the end of the 6-month period. In each visit, patients were assessed clinically (response to therapy, any adverse effects, and nutritional status), and biochemically including LFTs, which were repeated whenever symptoms or signs suggestive of hepatotoxicity (nausea, anorexia, malaise, vomiting, hepatomegaly, or jaundice) occur.

Exclusion of other causes of liver disease

Before attributing hepatotoxicity to anti-TB drugs, other causes of liver diseases were excluded by: IgM anti- 
hepatitis A virus antibody, $\mathrm{HBsAg}, \operatorname{IgM}$ anti-HBc in addition to the HBV DNA if the $\mathrm{HBsAg}$ and/or $\mathrm{HBcAb}$ are positive, anti-HCV antibody and HCV RNA if the anti$\mathrm{HCV}$ antibody is positive, autoimmune screen (anti-nuclear and anti-smooth muscle antibodies), and abdominal ultrasound to asses for liver abscesses, focal lesions, or biliary obstruction.

\section{Management of DIH}

INH, RIF, and PZA were stopped immediately in all patients who developed anti-TB-DIH when serum transaminases levels were more than 3 times the ULN in the presence of symptoms or more than 5 times the ULN with or without symptoms. LFTs were monitored weekly for 2 weeks, and then fortnightly. Two other anti-TB medications without hepatotoxicity, namely, EMB and streptomycin, were used until the cause of the hepatitis is identified. Anti-TB medications (INH, RIF, and PZA) were restarted once transaminases levels return back to less than 2 times the ULN. In patients with elevated baseline transaminases from pre-existing liver disease, drugs were restarted when the enzymes return to baseline levels. AntiTB drugs were reintroduced with RIF, followed by INH, and then PZA as previously reported [13]. If a patient again develops hepatotoxicity, the causative drug was permanently discontinued [14].

\section{Statistical analysis}

Data were collected in a specialized Data Collection Form, and then entered in the Statistical Package for Social Sciences (SPSS, version 15.0; SPSS Inc., Chicago, IL) for Windows. Data are expressed as mean \pm SD and frequencies as appropriate. Data were compared through Student's $t$ test and $\chi^{2}$ analysis for continuous variables and proportions, respectively. Elevations in serum AST and ALT levels (pretreatment levels vs. peak levels during treatment) were analyzed by paired $t$ test. Risk factors for $\mathrm{DIH}$ were evaluated by multivariate logistic regression analyses. Statistical significance was accepted at $P<0.05$.

\section{Results}

Baseline patients' characteristics are shown in Table 1. One hundred patients were included in this prospective study, 44 (44\%) male and 56 (56\%) females, with mean \pm SD age $33.60 \pm 13.03$ years. The mean \pm SD BMI was $20.29 \pm$ $4.38 \mathrm{~kg} / \mathrm{m}^{2}$. A total of $37(37 \%)$ patients had active pulmonary TB and 63 (63\%) patients had active extrapulmonary TB. As shown in Table 2, extra-pulmonary TB involved the pleura in 23 patients (23\%), lymph node in 20 patients $(20 \%)$, the peritoneum in 16 patients $(16 \%)$, and other sites in the remaining 4 patients $(4 \%)$.

During the study period, anti-TB-DIH was detected clinically and confirmed biochemically in 15 patients (15\%; Fig. 1). The time interval from onset of therapy and the detection of hepatotoxicity ranged from 15 to 60 days (median: 30 days). Twelve patients had alteration in LFTs within 2-4 weeks, whereas the rest $(n=3)$ showed alteration after 2 months of treatment. The time interval from the onset of hepatotoxicity to normalization of LFTs was 15-45 days (median: 15 days). Almost $60 \%$ of patients had normalization of their LFTs within 2 weeks of cessation of anti-TB therapy.

The clinical manifestations of DIH were nausea, anorexia, and malaise in $10(66.7 \%)$ patients, vomiting in 2 $(13.3 \%)$ patients, jaundice in $5(33.3 \%)$ patients, and encephalopathy in $1(6.7 \%)$ patient (Table 3). Anti-TB therapy was stopped temporarily until their clinical and biochemical profiles normalized. None of the patients had recurrence of hepatotoxicity with the reintroduction of antiTB drugs.

Death was reported in 1 case because of fulminant hepatic failure that developed 3 weeks after the onset of therapy. This case belonged to a 21-year-old woman with pulmonary TB and positive serology for HCV. Her BMI was $17.53 \mathrm{~kg} / \mathrm{m}^{2}$ and she was on INH, RIF, PZA, and streptomycin. Her hepatic failure progressed till she died 3 weeks later despite discontinuation of all her anti-TB drugs and supportive measures; liver transplantation was not feasible.

Administration of anti-TB drugs lead to slight, but statistically significant, elevations in transaminases levels in all patients $(n=100 ; P=0.02$ for ALT and $P=0.00$ for AST). All patients developing DIH $(n=15)$ showed significant rise in ALT and AST levels, which did not exceed 5 times the ULN in all of them. A rise in bilirubin level was detected in 7 patients only, 4 of them had increase of more than $3 \mathrm{mg} / \mathrm{dl}$ (Table 4).

There was no statistically significant difference in the incidence of DIH between patients with pulmonary TB and those with extra-pulmonary TB (Table 2). However, patients with pre-existing liver disease (liver cirrhosis, fatty liver, or diffuse hepatic pathology) were found to be at higher risk for anti-TB-DIH $(P=0.024$; OR: 3.60; 95\% CI: 1.16-11.18; Table 4). Also, patients with BMI of less than $20 \mathrm{~kg} / \mathrm{m}^{2}(P=0.037$; OR: 3.73; 95\% CI: $1.04-10.56)$ and those with serum albumin levels of less than $3.5 \mathrm{mg} / \mathrm{dl}(P=$ 0.035; OR: 3.31 ; 95\% CI: $1.04-10.56)$ were found to be at higher risk for anti-TB-DIH. Seven of the fifteen patients who developed DIH had positive sputum smear for acidfast bacilli, which may indicate that open pulmonary TB has a probable role in predisposing the patient to DIH $(P=$ 0.033; OR: 3.50; 95\% CI: 1.11-11; Table 5). In the 
Table 1 Baseline patients' characteristics

\begin{tabular}{llll}
\hline Variable & All patients $(n=100)$ & Patients without DIH $(n=85)$ & Patients with DIH $(n=15)$ \\
\hline $\begin{array}{l}\text { Mean age, years } \\
\text { Gender }\end{array} \quad 33.60 \pm 13.03$ & $33.16 \pm 13.12$ & $36.07 \pm 12.69$ \\
$\quad$ Men & $44(44 \%)$ & $48(56.5 \%)$ & $37(43.5 \%)$ \\
$\quad$ Women & $56(56 \%)$ & $8(35.3 \%)$ & $7(46.7 \%)$ \\
Height, $\mathrm{m}$ & $162.87 \pm 9.73$ & $162.67 \pm 9.71$ & $164 \pm 10.8$ \\
Weight, kg & $53.61 \pm 11.19$ & $54.12 \pm 11.05$ & $50.73 \pm 11.97$ \\
BMI, kg/m & $20.29 \pm 4.38$ & $20.54 \pm 4.37$ & $18.88 \pm 4.30$ \\
Albumin, g/l & $36.57 \pm 7.59$ & $37.33 \pm 7.44$ & $37.33 \pm 7.44^{\mathrm{b}}$ \\
Bilirubin, $\mu \mathrm{mol} / \mathrm{l}$ & $7.42 \pm 3.87$ & $7.14 \pm 4.04$ & $7.81 \pm 2.71$ \\
ALT, U/l & $17.27 \pm 12.38$ & $17.53 \pm 13.15$ & $15.87 \pm 6.73$ \\
AST, U/l & $28.50 \pm 14.89$ & $28.78 \pm 15.44$ & $27 \pm 11.67$ \\
\hline
\end{tabular}

Note: ALT, alanine aminotransferase; AST, aspartate aminotransferase; BMI, body mass index; DIH, drug-induced hepatotoxicity; $n=$ number

${ }^{a}$ Data expressed as mean \pm SD except gender (number (percentage))

b $P<0.05$ as compared with non-DIH group

Table 2 Hepatotoxicity among patients with different clinical varieties of tuberculosis ${ }^{\mathrm{a}}$

\begin{tabular}{lllllc}
\hline Clinical variety & \multicolumn{2}{c}{ Varieties of tuberculosis } & & \multicolumn{2}{c}{ Hepatotoxicity } \\
\cline { 2 - 3 } \cline { 5 - 6 } \cline { 5 - 6 } & $n$ & & & $n$ & $\%$ \\
\hline Pulmonary & 37 & 37 & & 21.6 \\
Pleural effusion & 23 & 23 & & 4 & 17.4 \\
Lymph node & 20 & 20 & & 0 & 0 \\
Abdominal & 16 & 16 & & 2 & 12.5 \\
$\quad$ Peritonial & 14 & 14 & & 1 & 7.1 \\
$\quad$ Intestinal & 2 & 2 & & 1 & 50 \\
Pericardial & 1 & 2 & & 0 \\
Genital & 2 & 1 & & 0 \\
Cutaneous & 1 & 1 & & 0 \\
\hline
\end{tabular}

${ }^{\mathrm{a}} P=0.08$ by $\chi^{2}$ analysis when compared with drug-induced hepatotoxicity in patients with pulmonary TB $(n=37)$ versus those with extra-pulmonary TB $(n=67)$

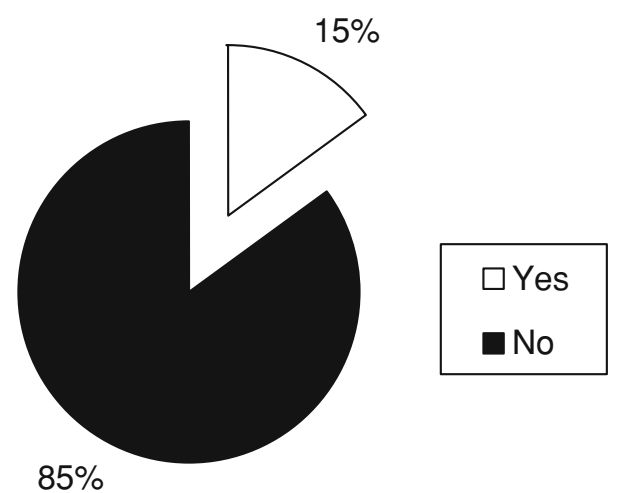

Fig. 1 Incidence of anti-TB drug-induced hepatotoxicity in patients with tuberculosis $(n=100)$
Table 3 Clinical presentations of anti-TB DIH

\begin{tabular}{llc}
\hline Variable & \multicolumn{2}{l}{ Patients with anti-TB-DIH $(N=15)$} \\
\cline { 2 - 3 } & $n$ & $\%$ \\
\hline Nausea & 10 & 66.7 \\
Anorexia & 10 & 66.7 \\
Malaise & 10 & 66.7 \\
Vomiting & 2 & 13.3 \\
Jaundice & 5 & 33.3 \\
Encephalopathy & 1 & 6.7 \\
\hline
\end{tabular}

Note: $n$, number; DIH, drug-induced hepatotoxicity

Table 4 Alterations in liver function tests in the patients who developed anti-TB DIH

\begin{tabular}{lll}
\hline Variable & \multicolumn{2}{c}{ Patients with anti-TB DIH $(N=15)$} \\
\cline { 2 - 3 } & $n$ & $\%$ \\
\hline ALT in all the 15 cases & \\
$\leq 3$ times ULN & 9 & 60.00 \\
3-4 times ULN & 4 & 26.67 \\
$>4$ times ULN & 2 & 13.33 \\
AST in all the 15 cases & & \\
$\leq 3$ times ULN & 8 & 53.33 \\
3-4 times ULN & 6 & 40.00 \\
$>4$ times ULN & 1 & 6.67 \\
Raised bilirubin in 7 cases & \\
1.5-2 mg/dl & 2 & 28.57 \\
2-3 mg/dl & 1 & 14.29 \\
$>3$ mg/dl & 4 & 57.14 \\
\hline
\end{tabular}

Note: ULN, upper limit of normal; $n$, number; DIH, drug-induced hepatotoxicity; ALT, alanine aminotransferase; AST, aspartate aminotransferase 
Table 5 Risk factors for antiTB drug-induced hepatotoxicity by univariate analysis
Note: OR, odds ratio; CI, confidence interval

${ }^{\text {a }} \mathrm{HCV}$ infection was defined as positive serum anti-HCV antibody and HCV RNA by polymerase chain reaction

${ }^{b}$ HBV infection was defined as positive serum hepatitis $B$ surface antigen and HBV DNA by polymerase chain reaction

\begin{tabular}{|c|c|c|c|c|c|}
\hline \multirow[t]{2}{*}{ Variables } & \multicolumn{2}{|c|}{ Hepatotoxicity } & \multirow[t]{2}{*}{ OR } & \multirow[t]{2}{*}{$95 \% \mathrm{CI}$} & \multirow[t]{2}{*}{$P$} \\
\hline & $n$ & Rate, $\%$ & & & \\
\hline Gender & & & 0.88 & $0.29-2.65$ & 0.821 \\
\hline Men $(n=44)$ & 7 & 15.9 & & & \\
\hline Women $(n=56)$ & 8 & 14.3 & & & \\
\hline Age & & & 1.29 & $0.42-3.97$ & 0.434 \\
\hline$>35$ years $(n=65)$ & 6 & 13.8 & & & \\
\hline$\leq 35$ years $(n=35)$ & 9 & 17.1 & & & \\
\hline Albumin level, g/dl & & & 3.31 & $1.04-10.56$ & 0.035 \\
\hline$\geq 3.5(n=58)$ & 5 & 8.6 & & & \\
\hline$<3.5(n=42)$ & 10 & 23.8 & & & \\
\hline Body mass index, $\mathrm{kg} / \mathrm{m}^{2}$ & & & 3.73 & $1.04-10.56$ & 0.037 \\
\hline$\geq 20(n=44)$ & 3 & 8.6 & & & \\
\hline$<20(n=56)$ & 12 & 21.4 & & & \\
\hline Pre-existing liver disease & & & 3.60 & $1.16-11.18$ & 0.024 \\
\hline No $(n=66)$ & 6 & 9.1 & & & \\
\hline Yes $(n=44)$ & 9 & 26.5 & & & \\
\hline Hepatitis $\mathrm{C}$ virus ${ }^{\mathrm{a}}$ & & & 3.07 & $0.81-11.69$ & 0.088 \\
\hline Negative $(n=87)$ & 11 & 12.6 & & & \\
\hline Positive $(n=13)$ & 4 & 30.8 & & & \\
\hline Hepatitis B virus $^{\mathrm{b}}$ & & & 0.85 & $0.78-0.92$ & 0.611 \\
\hline Negative $(n=97)$ & 15 & 15.5 & & & \\
\hline Positive $(n=3)$ & 0 & 0 & & & \\
\hline Abnormal baseline transaminases & & & 0.48 & $0.06-4.03$ & 0.430 \\
\hline No $(n=88)$ & 14 & 15.9 & & & \\
\hline Yes $(n=12)$ & 1 & 8.3 & & & \\
\hline Acid-fast bacilli in sputum & & & 3.50 & $1.11-11.00$ & 0.033 \\
\hline Negative $(n=67)$ & 8 & 10.5 & & & \\
\hline Positive $(n=24)$ & 7 & 29.2 & & & \\
\hline Severity of disease & & & 0.37 & $0.07-1.85$ & 0.201 \\
\hline Minimal $(n=15)$ & 5 & 31.3 & & & \\
\hline Moderate/advanced $(n=21)$ & 3 & 14.3 & & & \\
\hline Use of pyrazinamide & & & 0.97 & $0.28-3.33$ & 0.587 \\
\hline No $(n=26)$ & 4 & 15.4 & & & \\
\hline Yes $(n=74)$ & 11 & 14.9 & & & \\
\hline
\end{tabular}

multivariate logistic regression analysis, only pre-existing liver disease $(P=0.024$; OR: $0.259 ; 95 \% \mathrm{CI}: 0.08-0.83)$ and BMI less than $20 \mathrm{~kg} / \mathrm{m}^{2}(P=0.047$; OR: $0.25 ; 95 \% \mathrm{CI}$ : $0.63-0.98)$ were found to be independent predictors of antiTB-DIH (Table 6).

As shown in Table 5, there was no significant difference between patients who developed DIH and those who did not regarding other variables, such as age, sex, and raised baseline AST, ALT, or the inclusion of PZA in the treatment regimen. While inactive $\mathrm{HBV}$ carriers were not found to be at a higher risk for anti-TB-DIH, inactive HCV carriers appear at a higher risk although it did not reach statistical significance $(P=0.088$; OR: 3.07; 95\% CI: 0.81-11.69).
Table 6 Independent risk factors for anti-TB drug-induced hepatotoxicity by multivariate analysis

\begin{tabular}{lrrrrr}
\hline Variables & \multicolumn{2}{l}{ Hepatotoxicity } & OR & $95 \%$ CI & $P$ \\
\cline { 2 - 4 } & $n$ & Rate, $\%$ & & & \\
\hline Body mass index, $\mathrm{kg} / \mathrm{m}^{2}$ & & & 0.25 & $0.03-0.98$ & 0.047 \\
$\quad \geq 20(n=44)$ & 3 & 8.6 & & & \\
$\quad<20(n=56)$ & 12 & 21.4 & & & \\
Pre-existing liver disease & & & 0.26 & $0.08-0.83$ & 0.024 \\
$\quad$ No $(n=66)$ & 6 & 9.1 & & & \\
$\quad$ Yes $(n=44)$ & 9 & 26.5 & & & \\
\hline
\end{tabular}

Note: OR, odds ratio; CI, confidence interval; $n$, number 


\section{Discussion}

The use of multidrug regimens for the treatment of TB, such as the combination of INH, RIF, and PZA, has been associated with an increased incidence of hepatotoxicity when compared with INH monotherapy used for anti-TB prophylaxis $[5,15]$. The incidence of anti-TB-DIH varies worldwide and has been reported to be higher in developing countries where factors such as acute or chronic liver disease, indiscriminate use of drugs, malnutrition, and more advanced TB have been implicated [16-18]. However, it is unclear if these are independent risk factors for hepatotoxicity. In our study, $15 \%$ of the patients developed anti-TB-DIH, an incidence similar to reports from Asia $(8.0-19.8 \%)$ [14, 19-21], and higher than those from the West $(4.3 \%)$ [22].

The variation in the incidence of anti-TB-DIH may be related to differences in patients' characteristics, regimens used, type of monitoring, and the diagnostic criteria defining hepatotoxicity [23]. Despite these variations, the issue of anti-TB DIH remains important, especially in countries that are endemic for both TB and liver diseases as the case in Africa, Asia, and South America, and is expected to increase in the developed countries with the well-known rise of TB in the era of immunosuppressive therapy.

Anti-TB-DIH in our patients manifested as anorexia, nausea, vomiting, and jaundice, and occurred 15-60 days (median: 30 days) after initiation of therapy. This was in agreement with the results of Shakya et al. [20], who reported an interval of 12-60 days (median: 28 days). Similarly, Mahmood et al. [14] reported that the onset of anti-TB-DIH in almost two thirds of their patients $(41 / 67)$ was within 14 days from the start of therapy. This emphasizes the importance of close and more frequent monitoring of patients in the first 2 months of anti-TB therapy.

In the present study, the interval from the onset of hepatotoxicity to LFTs normalization was 15-45 days (median: 15 days). In almost three fifths of patients, their LFTs normalized within 2 weeks. Also, Mahmood et al. [14] reported that in four fifths of patients, their LFTs normalized within 2 weeks. In addition, Shakya et al. [20] reported that liver enzymes returned to the normal level within few days of cessation of therapy.

Several studies suggested that increasing age is a potential risk factor for anti-TB-DIH [14, 21, 24-28]. One study reported that the rate of anti-TB-DIH ranges from 2 to $8 \%$ as age increases, with an average of $5 \%$ [28]. Other studies reported that hepatotoxicity ranges from 22 to $33 \%$ in patients older than 35 years compared with a range from 8 to $17 \%$ in those younger than 35 years [21, 29]. Also, Mahmood et al. [14] reported that older age group was affected more than the younger age group (25.8 and $14.4 \%$, respectively). In contrast, Shakya et al. [20] reported that the incidence of anti-TB-DIH is higher in younger patients. This might be explained by the fact that the majority of patients enrolled in their study were young. This study and others [30] have showed that age is not a risk factor for the development of anti-TB-DIH.

Several studies reported that females are at increased risk of hepatotoxicity compared with males [24, 25, 31, 32]. However, this difference was not treatment limiting, nor statistically significant $[31,32]$. One study did show a 4-fold increase in the risk of treatment-limiting hepatotoxicity in women, but with an overall incidence of only 2\% [25]. Mahmood et al. [14] reported higher incidence of anti-TB-DIH in females than males (26.3\% vs. $19.7 \%)$. The higher vulnerability of females could be due to variations in pharmacokinetics and slower acetylation pattern [33] and/or lower BMI. Other studies, in agreement with ours, showed no increased risk of anti-TB-DIH in women [3, 27 , 30, 34-36].

Malnutrition may be a risk factor for anti-TB-DIH as detected by BMI of less than $20 \mathrm{~kg} / \mathrm{m}^{2}$ and serum albumin levels of less than $3.5 \mathrm{mg} / \mathrm{dl}$. This may be due to depletion of glutathione stores, which makes patients more vulnerable to oxidative injuries, and the slower pace at which their livers metabolize drugs. Indeed, low BMI and hypoalbuminemia were associated with higher rates of anti-TB-DIH in several studies [14, 16, 20, 28, 37-39].

Seven of the fifteen patients who had anti-TB-DIH in this study had positive sputum smear for acid-fast bacilli. This was also reported in another study in which 40 $(59.7 \%)$ patients were sputum smear positive and were more severely affected [14], indicating that patients with more extensive or open pulmonary TB are at an increased risk for anti-TB-DIH, necessitating more frequent and closer follow-up.

Inclusion of PZA in the regimen did not lead to more hepatotoxicity in our patients. This is consistent with earlier reports [17, 34, 40] and clinical trials [41, 42]. Some studies $[6,43,44]$, on the other hand, have indicated that the incidence of PZA-induced hepatotoxicity was significantly higher than that observed with the other first-line drugs.

Similar to the result of others $[3,7]$, we found that patients with pre-existing liver disease are at higher risk of anti-TBDIH. Indeed, an increased risk of hepatotoxicity during treatment of TB was observed in patients with abnormal baseline transaminases [45]. In the current study, inactive HBV carrier state was not a risk factor for anti-TB-DIH. However, our study included only 3 inactive HBV carriers. Previous studies showed more anti-TB-DIH in HBV carriers [34, 46, 47], whereas 1 did not [48]. Also, we observed a trend toward more anti-TB-DIH in inactive HCV carriers, although it did not reach statistical significance. A study on has 128 inpatients in Florida, approximately $30 \%$ of HCV- 
infected individuals developed anti-TB-DIH compared with $11 \%$ among uninfected individuals, and hepatitis $\mathrm{C}$ was an independent risk factor for the development of hepatotoxicity [49].

In our study, a 21-year-old woman died secondary to fulminant hepatic failure despite discontinuation of all antiTB drugs. It has been suggested that the severity of INHinduced hepatotoxicity may be worse or even fatal in women [11, 50]. Liver transplantation was the definitive therapy, but unfortunately was not available.

In conclusion, anti-TB-DIH is not uncommon, can be fatal, and is significantly more frequent in patients with pre-existing liver disease, malnourished patients, and those with hypoalbuminemia. Also, extensive or open pulmonary TB may have a role in predisposing patient to hepatotoxicity. Close follow-up, early recognition, and the immediate withdrawal of the causative agent are essential to prevent progression and allow the liver to heal. This topic is of higher importance in the developing countries where both TB and liver diseases are endemic.

Acknowledgments The authors thank all the nursing staff in the Chest Outpatient Clinic, Assiut University Hospital, Assiut, Egypt, for their assistance during the follow-up of these patients.

\section{References}

1. Cantwell MF, Snider DE, Cauthen GM, Onorato I. Epidemiology of tuberculosis in the United States, 1985 through 1992. J Am Med Assoc 1994;272:535-539

2. Peters BS, Carlin E, Weston RJ, Loveless SJ, Sweeney J, Weber $\mathrm{J}$, et al. Adverse effects of drugs used in the management of opportunistic infections associated with HIV infection. Drug Saf 1994;10:439-454

3. Kopanoff DE, Snider DE, Caras GJ. Isoniazid-related hepatitis. Am Rev Respir Dis 1978;117:991-1001

4. Franks AL, Binkin NJ, Snider DE, Rokaw WM, Becker S. Isoniazid hepatitis among pregnant and postpartum Hispanic patients. Public Health Rep 1989;104:151-155

5. Durand F, Bernuau J, Pessayre D, Samuel D, Belaiche J, Degott $\mathrm{C}$, et al. Deleterious influence of pyrazinamide on the outcome of patients with fulminant or subfulminant liver failure during antituberculous treatment including isoniazid. Hepatology 1995; 21:929-932

6. Schaberg T, Rebhan K, Lode H. Risk factors for side effects of isoniazid, rifampin and pyrazinamide in patients hospitalized for pulmonary tuberculosis. Eur Respir J 1996;9:2026-2030

7. Gronhagen-Riska C, Hellstrom PE, Froseth B. Predisposing factors in hepatitis induced by isoniazid-rifampin treatment of tuberculosis. Am Rev Respir Dis 1978;118:461-466

8. Hussain Z, Kar P, Husain SA. Antituberculosis drug-induced hepatitis: risk factors, prevention and management. Indian J Exp Biol 2003;41:1226-1232

9. Tanaogllu K. The management of anti-TB drug-induced hepatotoxicity. Int Union Tuberc Lung Dis 2001;5:65-69

10. Benichou C. Criteria for drug-induced liver disorder: report of an international consensus meeting. J Hepatol 1990;11:272-276

11. Saukkonen JJ, Cohn DL, Jasmer RM, Schenker S, Jereb JA, Nolan CM, et al. An official ATS statement: hepatotoxicity of antituberculosis therapy. Am J Respir Crit Care Med 2006; 174:935-952

12. Andrade RJ, Lucena MI, Fernández MC, Pelaez G, Pachkoria K, García-Ruiz E, et al. Drug-induced liver injury: an analysis of 461 incidences submitted to the Spanish registry over a 10 -year period. Gastroenterology 2005;129:512-521

13. Blumberg HM, Burman WJ, Chaisson RE, Daley CL, Etkind SC, Friedman LN, et al. American Thoracic Society/Centers for Disease Control and Prevention/Infectious Diseases Society of America: treatment of tuberculosis. Am J Respir Crit Care Med 2003;167:603-662

14. Mahmood K, Hussain A, Jairamani KL, Talib A, Abbasi B, Salkeen S. Hepatotoxicity with antituberculosis drugs: the risk factors. Pak J Med Sci 2007;23:33-38

15. Parthasarathy R, Sarma GR, Janardhanam B, Ramachandran P, Santha T, Sivasubramanian S, et al. Hepatic toxicity in South Indian patients during treatment of tuberculosis with short-course regimens containing isoniazid, rifampicin and pyrazinamide. Tubercle 1986;67:99-108

16. Mehta S. Malnutrition and drugs: clinical implications. Dev Pharmacol Ther 1990;15:159-165

17. Pande JN, Singh SPN, Khilnani GC, Khilnani S, Tandon RK. Risk factors for hepatotoxicity from antituberculosis drugs: a case-control study. Thorax 1996;51:132-136

18. Gangadharan PRJ. Isoniazid, rifampicin and hepatotoxicity. Am Rev Respir Dis 1986;133:963-965

19. Ohno M, Yamaguchi I, Yamamoto I, Fukuda T, Yokota S, Maekura R, et al. Slow $N$-acetyltransferase 2 genotype affects the incidence of INH and RMP-induced hepatotoxicity. Int J Tuberc Lung Dis 2000;4:256-261

20. Shakya R, Rao BS, Shrestha B. Evaluation of risk factors for anti tuberculosis drug induced hepatotoxicity in Nepalese population. Ann Pharmacother 2004;38:1074-1079

21. Huang YS, Chern HD, Su WJ, Wu JC, Lai SL, Yang SY, et al. Polymorphism of the $\mathrm{N}$-acetyltransferase 2 gene as a susceptibility risk factor for all antituberculosis drugs-induced hepatitis. Hepatology 2002;35:883-889

22. Steele MA, Burk RF, DesPrez RM. Hepatitis with INH and RMP: a meta-analysis. Chest 1991;99:465-471

23. Villor AF, Sopena B, Villor JF. The influence of risk factors on the severity of antituberculosis drug induced hepatotoxicity. Int $\mathrm{J}$ Tuberc Lung Dis 2004;8:1499-1505

24. Younossian AB, Rochat T, Ketterer JP, Wacker J, Janssens JP. High hepatotoxicity of pyrazinamide and ethambutol for treatment of latent tuberculosis. Eur Respir J 2005;26:462-464

25. Papastavros T, Dolovich LR, Holbrook A, Whitehead L, Loeb M. Adverse events associated with pyrazinamide and levofloxacin in the treatment of latent multidrug-resistant tuberculosis. Can Med Assoc J 2002;167:131-136

26. Ridzon R, Meador J, Maxwell R, Higgins K, Weismuller P, Onorato IM. Asymptomatic hepatitis in persons who received alternative preventive therapy with pyrazinamide and ofloxacin. Clin Infect Dis 1997;24:1264-1265

27. Huang YS, Chern HD, Su WJ, Wu JC, Chang SC, Chiang CH, et al. Cytochrome P450 2E1 genotype and the susceptibility to antituberculosis drug-induced hepatitis. Hepatology 2003;37:924-930

28. Smith CA, Wadelius M, Gough AC, Harrison DJ, Wolf CR, Rane A. A simplified assay for the arylamine $N$-acetyltransferase 2 polymorphism validated by phenotyping with isoniazid. J Med Genet 1997;34:758-760

29. Dufour DR, Lott JA, Nolte FS, Gretch DR, Koff RS, Seeff LB. Diagnosis and monitoring of hepatic injury: I. Performance characteristics of laboratory tests. Clin Chem 2000;46:2027-2049

30. Lee BH, Koh WJ, Choi MS, Suh GY, Chung MP, Kim H, et al. Inactive hepatitis B surface antigen carrier state and hepatotoxicity during antituberculosis chemotherapy. Chest 2005;127:1304-1311 
31. Attri S, Rana SV, Vaiphie K, Katyal R, Sodhi CP, Kanwar S, et al. Protective effect of $N$-acetylcysteine in isoniazid induced hepatic injury in growing rats. Indian J Exp Biol 2001;39:436-440

32. Sodhi CP, Rana SV, Mehta SK, Vaiphei K, Attri S, Thakur S, et al. Study of oxidative stress in isoniazid-induced hepatic injury in young rats with and without protein-energy malnutrition. J Biochem Toxicol 1996;11:139-146

33. Marvin W. Impacts of gender on drug responses. Drug Top 1998; 591-600

34. Sharma SK, Balamurugan A, Saha PK, Pandey RM, Mehra NK. Evaluation of clinical and immunogenetic risk factors for the development of hepatotoxicity during antituberculosis treatment. Am J Respir Crit Care Med 2002;166:916-919

35. LoBue PA, Moser KS. Isoniazid- and rifampin-resistant tuberculosis in San Diego County, California, United States, 19932002. Int J Tuberc Lung Dis 2005;9:501-506

36. Fountain FF, Tolley E, Chrisman CR, Self TH. Isoniazid hepatotoxicity associated with treatment of latent tuberculosis infection: a 7 -year evaluation from a public health tuberculosis clinic. Chest 2005;128:116-123

37. Sarma GR, Immanuel C, Kailasam S, Narayana AS, Venkatesan P. Rifampin-induced release of hydrazine from isoniazid: a possible cause of hepatitis during treatment of tuberculosis with regimens containing isoniazid and rifampin. Am Rev Respir Dis 1986;133:1072-1075

38. Scharer L, Smith JP. Serum transaminase elevations and other hepatic abnormalities in patients receiving isoniazid. Ann Intern Med 1969;71:1113-1120

39. Ferebee S, Mount F. Tuberculosis morbidity in a controlled trial of the prophylactic use of isoniazid among household contacts. Am Rev Respir Dis 1969;85:490-510

40. Girling DJ. The hepatic toxicity of antituberculosis regimens containing isoniazid, rifampicin and pyrazinamide. Tubercle 1978; 59:13-32
41. Combs DL, O'Brien RJ, Geiter LJ. USPHS tuberculosis short course chemotherapy trial 21: effectiveness, toxicity, and acceptability. Ann Intern Med 1990;112:397-406

42. British Thoracic Association. A controlled trial of six months chemotherapy in pulmonary tuberculosis. First Report: results during chemotherapy. Br J Dis Chest 1981;75:141-153

43. Ormerod LP, Horsfield N. Frequency and type of reactions to antituberculosis drugs: observations in routine treatment. Tuber Lung Dis 1996;77:37-42

44. Yee D, Valiquette C, Pelletier M, Parisien I, Rocher I, Menzies D. Incidence of serious side effects from first-line antituberculosis drugs among patients treated for active tuberculosis. Am J Respir Crit Care Med 2003;167:1472-1477

45. Teleman MD, Chee CB, Earnest A, Wang YT. Hepatotoxicity of tuberculosis chemotherapy under general programme conditions in Singapore. Int J Tuberc Lung Dis 2002;6:699-705

46. Wong WM, Wu PC, Yuen MF, Cheng CC, Yew WW, Wong PC, et al. Antituberculosis drug-related liver dysfunction in chronic hepatitis B infection. Hepatology 2000;31:201-206

47. Wu JC, Lee SD, Yeh PF, Chan CY, Wang YJ, Huang YS, et al. Isoniazid-rifampin-induced hepatitis in hepatitis B carriers. Gastroenterology 1990;98:502-504

48. Hwang SJ, Wu JC, Lee CN, Yen FS, Lu CL, Lin TP, et al. A prospective clinical study of isoniazid-rifampicin-pyrazinamideinduced liver injury in an area endemic for hepatitis B. J Gastroenterol Hepatol 1997;12:87-91

49. Ungo JR, Jones D, Ashkin D, Hollender ES, Bernstein D, Albanese AP, et al. Antituberculosis drug-induced hepatotoxicity: the role of hepatitis $\mathrm{C}$ virus and the human immunodeficiency virus. Am J Respir Crit Care Med 1998;157:1871-1876

50. Snider DE, Caras G. Isoniazid-associated hepatitis deaths: a review of available information. Am Rev Respir Dis 1992;145: 494-497 